\title{
Valuing Businesses In Cyclical Industries
}

Jeffrey W. Lippitt, Ithaca College, USA

Eric Lewis, Siena College, USA

\begin{abstract}
Given the potential sensitivity of business values to industry business cycles, it is imperative that valuators consider business cycles when executing valuations of firms that tend to be sensitive to these industry-level fluctuations. Failure to consider earnings cycles in industries where they are significant can result in extreme over and undervaluation of business enterprises. The methods presented in this paper can help a valuation professional to utilize industry cycle information to dramatically improve the quality of value estimates.
\end{abstract}

Keywords: Valuing Businesses in Cyclical Industries; Business Cycles and Business Values

\section{INTRODUCTION}

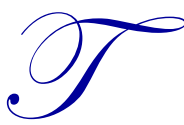

he current value of a business is generally accepted to be the present value of the future benefits of ownership. These benefits may be realized through immediate sale of the business, either as a going concern or in its component pieces, or through operation of the enterprise resulting in a stream of future benefits. Providing that the present value of the stream of future benefits exceeds the current market value of the component pieces, the enterprise's value will be based on the present value of the stream of future benefits whether the firm is sold as a going concern or held and operated. The techniques presented in this paper are relevant to situations where value is based on the stream of future benefits resulting from a going concern, and not on the market value of its component pieces.

The issues involved in valuing the future benefits that accrue to owners of an enterprise can be divided into two categories: measuring the future benefits and determining an appropriate capitalization rate for computing their present value. Future benefits are most often evaluated by reference to a measure of either adjusted accounting earnings or free cash flow. In practice, earnings or cash flows are examined for the 3 to 5 years ending on the valuation date and either an average or a weighted average of these amounts serves as the "base" earnings upon which the value will depend. A capitalization rate is generally determined by reference to market transactions in either the target firm or similar firms or through a "build-up" method where a broadly based market rate is adjusted in several steps, to reflect the specific conditions of the target firm. The capitalization rate can be thought of as the inverse of the price/earnings ratio. Dividing base earnings by the capitalization rate results in an estimate of firm value. This approach can be used fairly successfully when valuing firms that have either stable earnings or earnings with stable patterns of growth.

When a firm operates in an industry that is subject to pronounced business cycles, the valuation process becomes much more challenging. If one applies a simple earnings capitalization method to highly cyclic firms, large estimation errors are inevitably introduced. With stable earnings or stable growth, the firm's future looks similar at every point in time. Think of a hiker walking along a flat road. As the hiker progresses, the future prospects do not change in the sense that there are neither hills nor valleys. The recent past would be a good proxy for the future. If the hiker is walking on a road with a constant incline, again, the future prospects are the same from one point in time to the next. The recent past will provide a good indication of the future trajectory, providing some adjustment is made for the constant incline. Finally, consider a hiker walking a road the goes through an endless series of hills and valleys. The recent past could provide a very misleading indication of the future prospects. As the hiker comes down a hill and is approaching the bottom of the valley, the recent past would indicate low and declining future prospects, whereas the hiker is in fact facing a future of climbing. The same misleading indication would result as the hiker approaches the summit of a hill. The recent past indicates climbing, whereas the future will involve a downhill trip. As the hiker proceeds along the hilly trail, the future prospects are continually changing.

(C) 2012 The Clute Institute http://www.cluteinstitute.com/ 
All other things being equal, firms experiencing stable earnings or stable growth will have a stable relationship between recent earnings and value over time, providing that interest rates are stable. The firm with cyclic earnings is very similar to the hiker traversing the hilly terrain. The value of the firm is dependent upon future earnings and, as we move through time, the future earnings prospects change, thus changing the value of the firm. Not only are the future prospects changing, but they are changing in such a way that the most recent past earnings are likely to provide a misleading estimate of future earnings. Because of the changing future prospects, the relationship between recent earnings and value is continually changing as well. Use of the simple earnings capitalization method for firms experiencing cyclic earnings is likely to lead to significant errors if the valuation is not adjusted for the cycle.

\section{AN EXAMPLE}

As an illustration of this challenge, let us assume that a firm operates in an industry that goes through a 10 year earnings cycle. Further let us assume that the amplitude of the firm's earnings cycle is $\$ 500,000$ and is anchored on top of a $\$ 400,000$ component that is non-cyclical. In other words, the firm's earnings swing to a high of $\$ 900,000$ then to a low of $-\$ 100,000$ and back to $\$ 900,000$ over a ten year period. We can model these earnings as follows:

Earnings $\mathrm{s}_{\mathrm{t}}=(\operatorname{sine}(\mathrm{t} * \mathrm{D}) * 500,000)+400,000$

Where:

$\mathrm{D}=(2 * \pi) /$ Period

And:

Period $=10$

Both the $\pi$ and Sine functions can easily be accessed in Excel.

This results in the following earnings series:

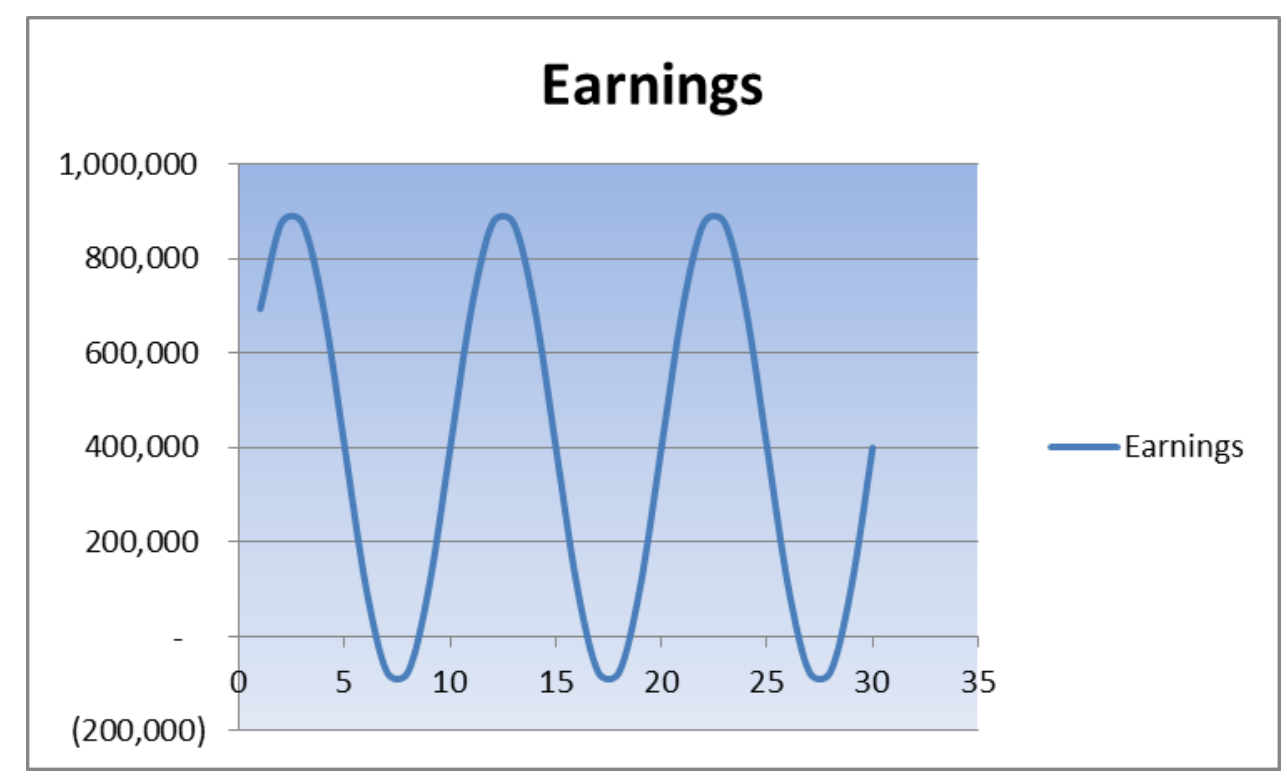

This earnings cycle can be forecast into the future, and each year's earnings discounted back to the present at an appropriate discount rate. At any point in time, the value of the firm is the present value of all the future earnings. 


$$
\text { Value }_{t}=\sum_{j=t+1}^{\infty}\left(\text { Earnings }_{j} *(1+k)^{-t}\right)
$$

Using a discount rate of $12 \%$, results in the following:

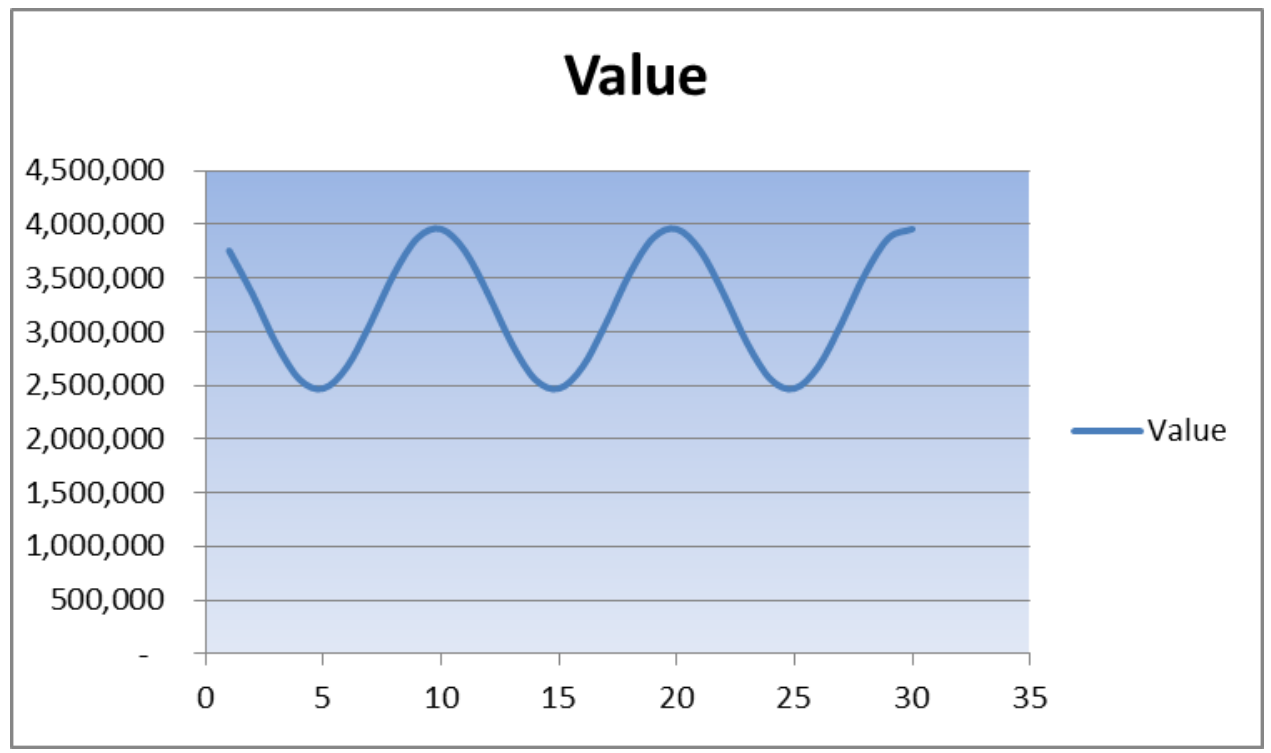

We can see that value cycles with a 10 year period just as earnings does. It is very interesting to note however, what we get if we plot earnings and value on the same graph.

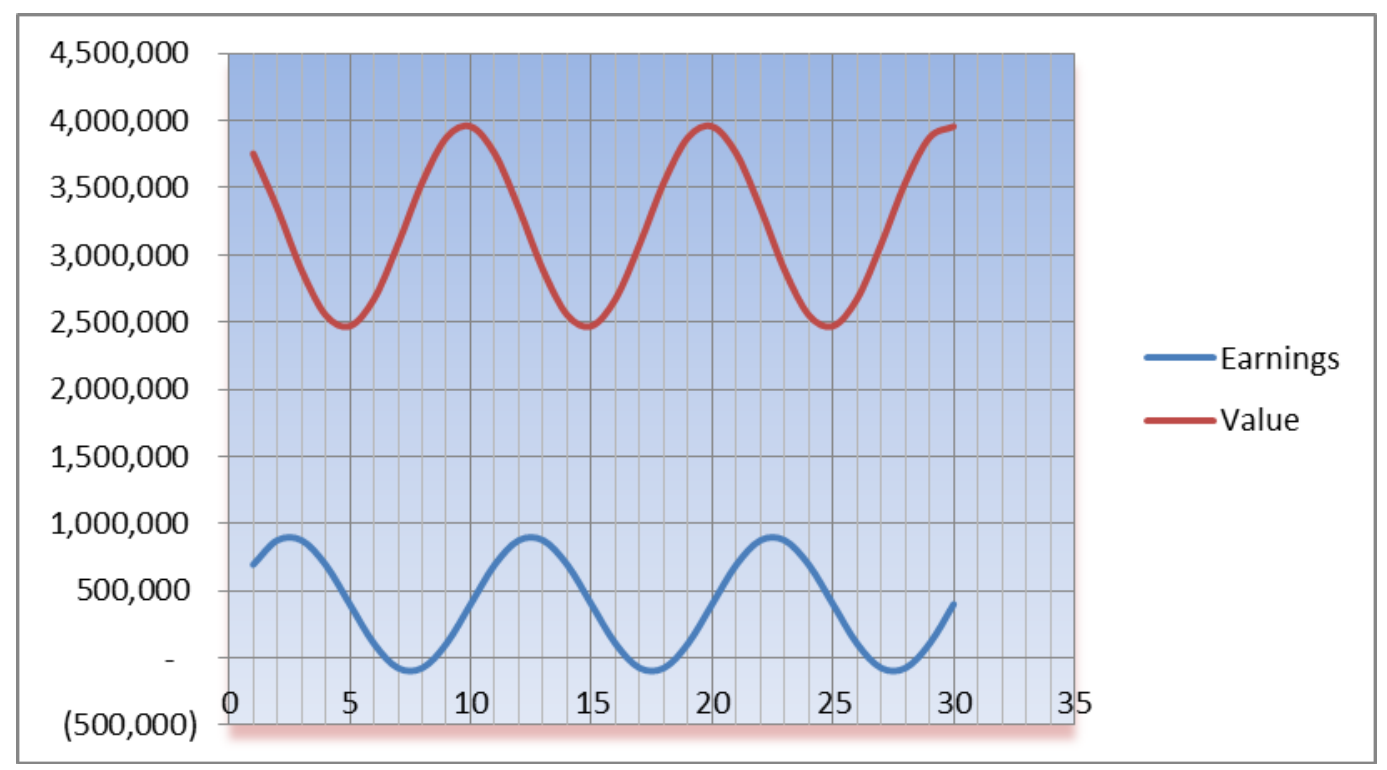

Careful examination of this graph shows that the value and the earnings series are not in phase. They have the same period, but reach highs and lows at different times. If we look at year 5, the value has reached a low of about $\$ 2,500,000$, whereas earnings are at $\$ 400,000$, or only about half way to the trough. At year 10, Value is at its peak of $\$ 4,000,000$, whereas earnings are again at about $\$ 400,000$ or half way to their peak. Because these series are out of phase, the relationship between value and earnings is not stable. If we calculate the price/earnings ratio, by dividing the value by earnings and plot the ratio over time we get the following: 


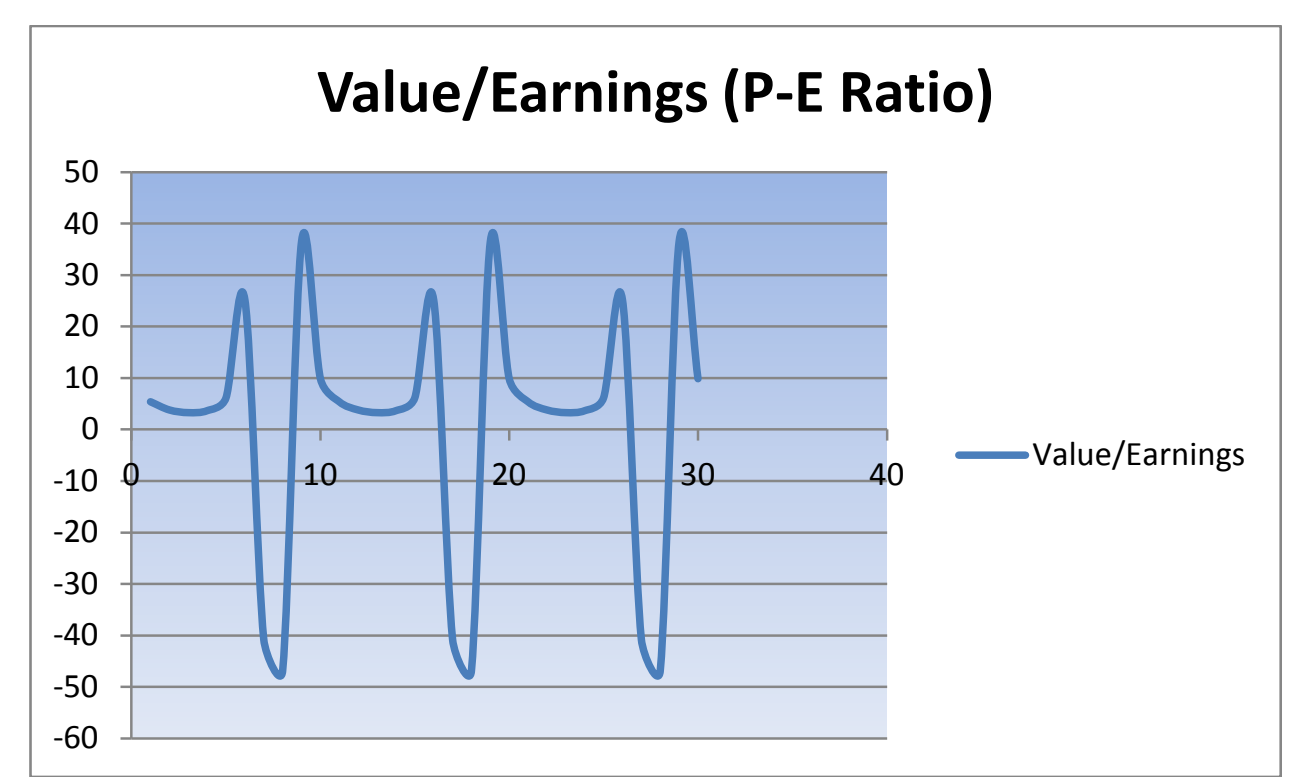

This unstable relationship between price and earnings raises questions about the standard application of the Earnings Capitalization Model, without adjustment for the industry cycle.

\section{PRACTICAL APPLICATION}

Generally when analysts are valuing a firm that has trends in its earnings, they use a weighted average of previous years' earnings to measure the "base" earnings. They then estimate a value by capitalizing these earnings. In order to demonstrate how values that are estimated using this approach compare to actual values, we introduce the following weighted earnings sequence:

$$
\text { Value }_{t}=\left(\frac{\left(3 * \text { Earnings }_{t}+2 * \text { Earning }_{t-1}+\text { Earning }_{t-2}\right)}{6}\right) / .12
$$

Calculating this amount and plotting it with the real value we get the following:

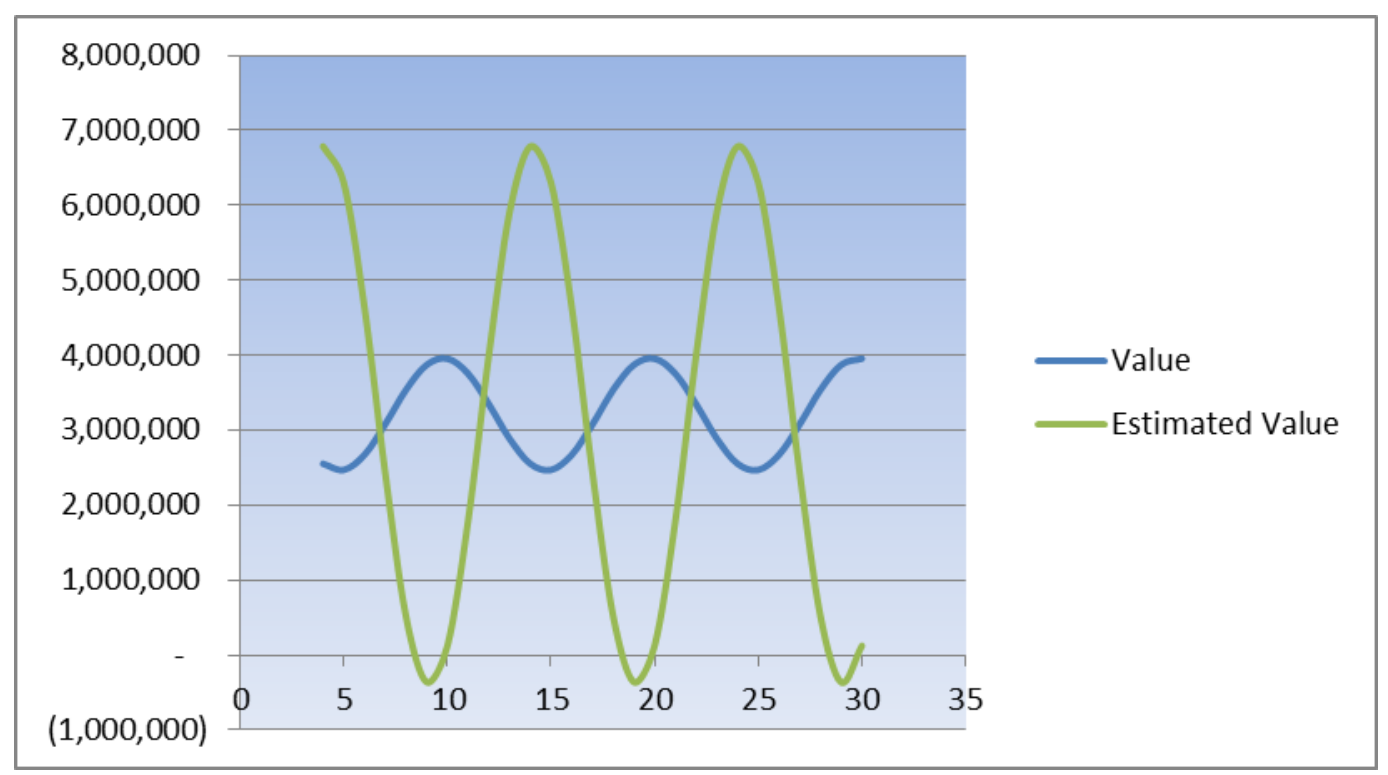


We can see that the estimated value also goes through a cycle with the same period as earnings and value, but it is almost exactly counter-cyclical. The estimated value dramatically overestimates and underestimates the actual value.

Note: When the estimated value goes below zero, the valuator is likely to base the value on the individual values of component pieces of the entity, rather than on future earnings. In fact, any time the estimated value falls below the value of the component pieces, the valuation will shift to an asset valuation. This would limit the extreme undervaluation that can occur, but is of little comfort given that these limits will emerge only when the real value of the firm is at a peak. There is no technical limit on the upside to prevent extreme overvaluation. In fact, extreme overvaluation occurs as the real value of the firm reaches a minimum in the value cycle. Not only does the unadjusted earnings capitalization model make significant errors of overvaluation and undervaluation, but these errors are out of phase with the real value. As the actual value is reaching a peak, the estimated value is near a trough.

Two indications are readily apparent. First, the failure to properly account for the industry cycle can result in dramatic errors of over or undervaluation. Second, the timing of transactions can dramatically change the valuation, even when the cycle is properly accounted for. Since the information about the cycle is unlikely to be firm specific, we can use information at the industry level to evaluate the cycle (See Pratt 2008). DeHeer and Koller (2000) also provide insight into the valuation of cyclical firms.

Under the conditions of our illustration, an investor investing in this company and holding for any given period, will earn just the rate of return used in discounting the future cash flows. This illustration therefore does not provide a roadmap on how to "buy low \& sell high".

Consider a business owner who wishes to transfer ownership of his business to his children and is concerned about gift tax. By choosing the low point in the value cycle he will be able to reduce the tax significantly over what it would be if the transfer were to take place at a high point in the value cycle. Note also, that choosing the low point of the value cycle is not the same as choosing the low point in the business cycle.

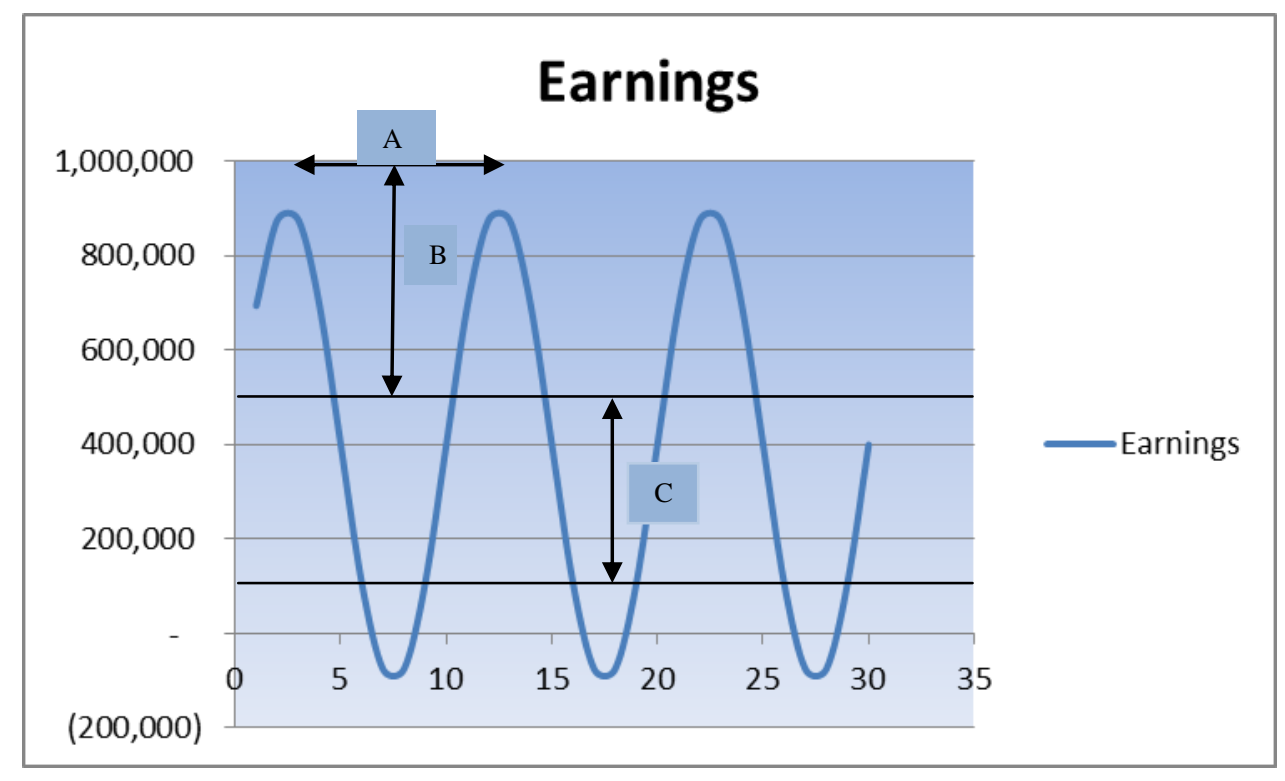

In order to make practical use of the value implications of cyclicality it is necessary to estimate four values that define the cyclical portion of an earnings pattern. These values are (noted in the chart above): 
- $\quad$ A - The peak-to-peak period - the time that elapses between peak earnings expectations (This is likely to be an industry-specific period, determinable through the industry references noted in this article and/or from industry publications)

- $\quad$ B - The amplitude of the cycle - defined as half of the distance between the peak and trough of the earnings expectation

- $\quad$ C - The Earnings Offset - the stable portion of earnings that is measured by taking the average of the peak and trough earnings expectations.

- $\quad$ Current position on the cycle curve. (This will behave as part of the peak-to-peak cycle noted above)

For information regarding business and industry cycles the National Bureau of Economic Research and the Economic Cycle research Institute (ECRI) provide both helpful guidance and data. Berman and Pfleeger (1997) and Petersen and Strongin (1996) provide insight into the cyclicality of specific industries, while Domowitz, Hubbard and Petersen (1998) focus on cyclical fluctuations in U.S. manufacturing. The amplitude and offset characteristics will be firm specific and must be estimated by the valuator using data provided by the sources above as well as individual company financial information. In addition it is necessary to establish a capitalization rate, as in any earnings-based valuation. Having observed or estimated these components, a valuator can predict future earnings and then execute a fairly standard earnings capitalization.

\section{CONCLUSION}

Given the potential sensitivity of firm value to industry cycles, it is imperative that valuation professionals consider these cycles when executing valuations of firms that tend to be sensitive to these fluctuations. Failure to consider earnings cycles in industries where they are significant can result in extreme over and undervaluation of business enterprises. The method presented above can help a valuation professional to utilize industry cycle information to dramatically improve the quality of value estimates and to avoid the extreme valuation errors that can occur in this context.

\section{EXTENSIONS}

A pilot empirical study on firms in two highly cyclical industries shows great promise for improving valuation accuracy in the context of significant industry cycles. More extensive empirical study in this area is needed in order to understand the full potential of incorporating these elements into existing valuation models.

\section{AUTHOR INFORMATION}

Jeffrey W. Lippitt, Ph.D. Jeff is an Associate Professor of Accounting at Ithaca College. He has held previous appointments at Union college and Rennselaer Polytechnic Institute. Dr. Lippitt's work has appeared in The Journal of Business Valuation and Economic Loss Analysis, the CPA Journal, the Journal of Legal Economics and several other academic and professional publications. His research focuses on Business Valuation issues, including valuing businesses and assets that present specific valuation challenges. Dr. Lippitt holds a PhD in Accounting from Penn State. E-mail: jlippitt@ithaca.edu

Eric E. Lewis, Ph.D. Eric is an Associate Professor of Accounting at Siena College. Eric has also held tenured appointments at Skidmore College, Union Graduate College, and Ithaca College, where he served as Chair of the Accounting Department from 2005-2009. Dr. Lewis has also held an appointment as a Visiting Associate Professor of Applied Economics at Cornell University's Dyson School of Applied Economics and Management. His research focuses on Business Valuation issues, including valuing businesses and assets that present specific valuation challenges. His work has been published in a variety of academic and professional publications. Eric holds an MBA and PhD in Accounting from Union College. E-mail: elewis@ siena.edu (Corresponding author)

\section{REFERENCES}

1. Berman, Jay, and Janet Pfleeger. "Which Industries are Sensitive to Business Cycles?" Monthly Labor Review (Feb. 1997): 19-25. Print. 
2. De Heer, Marco and Timothy M Koller. "Valuing Cyclical Companies" McKinsey Quarterly., 2000, 2, pp. 62-69.

3. Domowitz, Ian, R. Glenn Hubbard, and Bruce C. Petersen. "Market Structure and Cyclical Fluctuations in U.S. Manufacturing.” Rev. Econ. Stat., 1988, pp. 55-66.

4. ECRI. Economic Cycle Research Institute, n.d. Web. 14 Oct. 2011. http://businesscycle.com

5. National Bureau of Economic Research. The National Bureau of Economic Research, n.d. Web. 14 Oct. 2011. http://www.nber.org

6. Petersen, Bruce and Steven Strongin. "Why Are Some Industries More Cyclical Than Others?” J. Bus. Econ. Stat., April 1996, 14(2), pp. 189-198

7. $\quad$ Pratt, Shannon. "Chap. 6." Valuing a Business. 5th ed. New York: The McGraw-Hill Companies, 2008, pp. 103-127. 


\section{NOTES}

